\title{
Biobanking for glomerular diseases: a study design and protocol for KOrea Renal biobank NEtwoRk System TOward NExt-generation analysis (KORNERSTONE)
}

Eunjeong Kang ${ }^{1+}$, Yaerim Kim ${ }^{2 \dagger}$, Yong Chul Kim ${ }^{3 \dagger}$, Eunyoung Kim ${ }^{4}$, Nankyoung Lee ${ }^{5}$, Yeonghui Kim ${ }^{6}$, Soojin Lee ${ }^{3}$, Seungyeup Han², Misun Choe ${ }^{7}$, Jin Ho Hwang ${ }^{8}$, Sunhwa Lee ${ }^{9}$, Ji In Park', Jung Tak Park ${ }^{10}$, Beom Jin Lim ${ }^{11}$, Jung Pyo Lee ${ }^{12}$, Jung Nam An ${ }^{13}$, Dong-Ryeol Ryu', Jung-Hyun Kim ${ }^{14}$, Hee Gyung Kang ${ }^{15}$, Hyun Soon Lee ${ }^{16}$, Kyung Chul Moon ${ }^{17}$, Kwon Wook Joo ${ }^{3}$, Kook-Hwan Oh³ , Seung Seok Han ${ }^{3}$, Hajeong Lee ${ }^{3}$, Dong Ki Kim ${ }^{3 *}$ (D) and on behalf of the KORNERSTONE Study Group

\begin{abstract}
Backgrounds: Glomerular diseases, a set of debilitating and complex disease entities, are related to mortality and morbidity. To gain insight into pathophysiology and novel treatment targets of glomerular disease, various types of biospecimens linked to deep clinical phenotyping including clinical information, digital pathology, and well-defined outcomes are required. We provide the rationale and design of the KOrea Renal biobank NEtwoRk System TOward Next-generation analysis (KORNERSTONE).

Methods: The KORNERSTONE, which has been initiated by Korea Centres for Disease Control and Prevention, is designed as a multi-centre, prospective cohort study and biobank for glomerular diseases. Clinical data, questionnaires will be collected at the time of kidney biopsy and subsequently every 1 year after kidney biopsy. All of the clinical data will be extracted from the electrical health record and automatically uploaded to the web-based database. High-quality digital pathologies are obtained and connected in the database. Various types of biospecimens are collected at baseline and during follow-up: serum, urine, buffy coat, stool, glomerular complementary DNA (cDNA), tubulointerstitial cDNA. All data and biospecimens are processed and stored in a standardised manner. The primary outcomes are mortality and end-stage renal disease. The secondary outcomes will be deterioration renal function, remission of proteinuria, cardiovascular events and quality of life.

(Continued on next page)
\end{abstract}

\footnotetext{
*Correspondence: dkkim73@gmail.com

'Eunjeong Kang, Yaerim Kim and Yong Chul Kim contributed equally to this work.

${ }^{3}$ Department of Internal Medicine, Seoul National University Hospital, Seoul

National University College of Medicine, Seoul, South Korea

Full list of author information is available at the end of the article
}

(c) The Author(s). 2020 Open Access This article is licensed under a Creative Commons Attribution 4.0 International License, which permits use, sharing, adaptation, distribution and reproduction in any medium or format, as long as you give appropriate credit to the original author(s) and the source, provide a link to the Creative Commons licence, and indicate if changes were made. The images or other third party material in this article are included in the article's Creative Commons licence, unless indicated otherwise in a credit line to the material. If material is not included in the article's Creative Commons licence and your intended use is not permitted by statutory regulation or exceeds the permitted use, you will need to obtain permission directly from the copyright holder. To view a copy of this licence, visit http://creativecommons.org/licenses/by/4.0/. The Creative Commons Public Domain Dedication waiver (http://creativecommons.org/publicdomain/zero/1.0/) applies to the data made available in this article, unless otherwise stated in a credit line to the data. 
(Continued from previous page)

Discussion: Ethical approval has been obtained from the institutional review board of each participating centre and ethics oversight committee. The KORNERSTONE is designed to deliver pioneer insights into glomerular diseases. The study design allows comprehensive, integrated and high-quality data collection on baseline laboratory findings, clinical outcomes including administrative data and digital pathologic images. This may provide various biospecimens and information to many researchers, establish the rationale for future more individualised treatment strategies for glomerular diseases.

Trial registration: NCT03929887.

Keywords: Nephrology, Pathology, Glomerulonephritis

\section{Background}

The prevalences of chronic kidney disease (CKD) and end-stage renal disease (ESRD) are continuously increasing around the world. Recent evidence indicates that the number of incident ESRD patients due to glomerular diseases is increasing [1, 2], and many additional ESRD cases are expected to have been attributed to glomerular diseases, considering the cases that have not been confirmed by kidney biopsy. However, the discovery of pathognomonic biomarkers and disease-specific therapeutic targets for glomerular diseases is limited.

To better understand the pathophysiology, biomarkers, and treatment targets of glomerular diseases and ultimately to improve clinical outcomes, it is imperative to translate and integrate research with various types of biospecimen linked to deep clinical phenotyping, including clinical information, self-questionnaires, digital pathology and outcomes from the electronic health record (EHR) and administrative data. A significant additional number of kidney disease cohorts were established through several international consortiums. The C-PROBE, [3] ERCB cohort [4] with CKD patients, and Nephrotic Syndrome Study Network (NEPTUNE) cohort [5] for patients with nephrotic syndrome were started in approximately 2010, and these cohorts are relatively small. Recently, large-scale genomics consortia, including CKDGen [6] and EURenOmics, [7] have been activated in the United States and Europe. However, these cohorts are not sufficient to support data for Asians. To that end, a multicentre prospective cohort based on deep clinical phenotypes, biospecimens, and digital pathology has been established in Korea, the 'KORNERSTONE', which is supported by the Korea Centers for Disease Control and Prevention (KCDC).

The objectives of the KORNERSTONE are as follows: 1) establish a collaborative, innovative deep clinical phenotypebased investigational infrastructure to carry out clinical and translational studies of glomerular disease; 2) perform a longitudinal observational cohort study of patients with biopsy-proven glomerular diseases; and 3) gain insight into the pathophysiology, natural history and novel treatment targets of glomerular diseases. In the present paper, we report the KORNERSTONE design and methods in detail.

\section{Methods/design \\ Ethics statements}

The basic protocol of this study was approved by the ethics committee of each participating centre, including the institutional review boards of Seoul National University (1404-117-575), Keimyung University Dongsan Hospital (DSMC 2019-04-015-001), Chung-Ang University (1942005-369), Severance Hospital (2019-0463-001), Boramae Medical Center (L-2019-126), and Kangwon National University Hospital (KUNH-2019-05-009). Additionally, the ethics oversight committee of the KORNERSTONE reviewed the design and protocols of this study. All of the ethical issues regarding the plans of the KORNERSTONE cohort study will be supervised by this committee.

\section{Study design and population}

The KORNERSTONE is a prospective multicentre observational biobank, databank and digital pathology repository of patients with glomerular disease in Korea (NCT 03929887 at http://www.clinicaltrials.gov). Nephrologists working in six clinical centres in the major university-affiliated hospitals, pathologists, and paediatricians are participating in this study. Among the six clinical centres, four centres are located in the metropolitan city of Seoul, one is in the southern area, and the last centre is in northeastern Korea.

Patients suspected of glomerular diseases who received kidney biopsy in participating university medical centres are eligible for inclusion in the KORNERSTONE. Patients who previously received a kidney transplant will be excluded. This study will enrol 3000 children (age $<18$ years) and adults. Eligible participants will be screened at the inpatient or outpatient clinic of the department of nephrology or paediatrics of each participating hospital. Participants who pass an initial screening and agree to participate will provide written informed consent during their visit. Parents of all children, and children themselves if age more than 6 years, provided written informed consent. Informed consent includes utilization, collection, and provision of demographics, clinical information, and social security number for the linkage of administrative data and biospecimens. When a participant wants to withdraw 
from the KORNERSTONE, all stored biospecimens and data will be destroyed or deleted. All of the laboratory data, self-questionnaires and biospecimens will be collected at the time of kidney biopsy for the baseline information (Table 1). Patients or the public were not involved in the design, or conduct, or reporting, or dissemination plans of our research.

\section{Sample size consideration}

Table 2 summarizes the statistical power for time-to-event analyses (minimum detectable hazard ratio [MDHR]). For illustration, MDHRs were described for comparisons between two groups of equal size, which could represent any subgroups of interest (e.g., genetic risk alleles, treatment exposures, and clinical diagnosis). Clinical outcome event rates, including ESRD, death and complete remission, were based on published articles and early observed data in other glomerular disease cohorts [8-11].

\section{Clinical, patient-oriented outcomes and follow-up}

After enrolment, all of the participants will be assessed for whether they reach clinical endpoints each time they visit the outpatient clinic. The clinical endpoints of this study were divided into two categories: 1) deterioration of clinical outcomes was defined by doubling of serum $\mathrm{Cr}$ or decrease in estimated glomerular filtration rate (eGFR) by more than 30\%, and 2) improvement of clinical outcomes was defined by the remission of glomerulonephritis and proteinuria $<0.3 \mathrm{~g} /$ day. Other hard outcomes were defined by ESRD, cardiovascular events, and death. The patients who have proteinuria < $0.3 \mathrm{~g} /$ day at baseline have no improvement in clinical outcomes.

Whether the enrolled patients reached each clinical endpoint will be confirmed by the EHR. If the participant displays deterioration, improvement of clinical outcomes, ESRD or cardiovascular events, laboratory findings, urinalysis, and biospecimens, including serum, plasma, buffy coat, and urine, will be collected from the participants. Stools will be collected at baseline only. Additionally, the same information and biospecimens will be collected from the participants at least once per year.

In addition, the patient-oriented outcome will be secured by age-appropriate questionnaires. These outcomes will include symptoms from the patient's perspective, functional status, nutritional status and health-related quality of life. The questionnaires will be collected every year.

All of the administrative data from Statistics Korea, Health Insurance Review and Assessment Service (HIRA) and National Health Insurance Service (NHIS) and ESRD registry data from the Korean Society of Nephrology will be linked through social security numbers or birth date. However, the information will not be stored by the researchers and will only be used for the collection of clinical outcome information under the approved protocol. The prescribed medication and diagnosis defined by the 10th revision of the International Statistical Classification of Diseases and Related Health Problems (ICD-10) will be collected by HIRA and NHIS. The mortality and the cause of death will be obtained from Statistics Korea data. The reached ESRD outcomes, including dialysis and kidney transplantation, will be determined using the data from NHIS and the Korean ESRD registry from the Korean Society of Nephrology (Fig. 1). For clinical hard outcomes, including death and ESRD, the EHR of each participating centre and various administrative data will be used, so the outcome can be reliably determined even in the case of patient transfer to another hospital or of patients who cannot participate this cohort for other reasons.

\section{Electronic health record and questionnaires}

The detailed protocol for clinical data and questionnaire collection is described in Table 1. The eligible patients will be evaluated at baseline for demographic information, smoking history, chief complaints, and anthropometric information, including height, weight, and blood pressure. Measurements of the resting blood pressure in the inpatient setting on the kidney biopsy date using an electronic sphygmomanometer will be carried out.

We will collect laboratory findings closest to the kidney biopsy date. Serum creatinine will be measured using an isotope dilution mass spectrometry (IDMS) traceable method. The eGFR will be calculated using the Chronic Kidney Disease Epidemiology Collaboration (CKD-EPI) equation for adults. In children younger than 18 years, the creatinine-cystatin C-based CKiD (Chronic Kidney Disease in Children) equation will be used. Blood laboratory tests, such as complete blood cell count; chemistry, including calcium, phosphorus, total protein, and albumin; lipid panel; electrolyte panel; viral serology, and glomerular disease-related serology will be conducted. Quantitative tests of proteinuria and albuminuria will also be carried out. The information on prescribed medication will include the start and end date of each medication, doses per der day, and total number of prescription days.

The subjects will complete age-appropriate questionnaires concerning the quality of life using Kidney Disease and Quality of Life Short Form (KDQOL-SF) version 1.3, socioeconomic status, educational level, physical activity, health behaviours, health care facility utilization, and nutritional status using semi-food frequency questionnaires (semi-FFQs) and a food diary.

\section{Human biospecimen collection, quality control and standard operating procedure (SOP)}

Eight types of biospecimens will be collected: plasma, serum, buffy coat, genomic DNA, urine, stools, stool 
Table 1 List of clinical information and biospecimens in the KORNERSTONE

\begin{tabular}{|c|c|c|c|c|c|c|c|c|c|c|}
\hline Parameters & Detailed information & Screening & Baseline & $\begin{array}{l}1 \\
Y\end{array}$ & $\begin{array}{l}2 \\
Y\end{array}$ & $\begin{array}{l}3 \\
Y\end{array}$ & $\begin{array}{l}4 \\
Y\end{array}$ & $\begin{array}{l}5 \\
Y\end{array}$ & $\begin{array}{l}\text { Improvement or } \\
\text { deterioration of } \\
\text { clinical outcomes }\end{array}$ & $\begin{array}{l}\text { Hard } \\
\text { outcomes } \\
\text { (ESRD, CV } \\
\text { outcomes) }\end{array}$ \\
\hline $\begin{array}{l}\text { Informed } \\
\text { consent }\end{array}$ & & $\mathrm{O}$ & & & & & & & & \\
\hline $\begin{array}{l}\text { Demographic } \\
\text { information }\end{array}$ & & O & & & & & & & & \\
\hline Medical history & & $\mathrm{O}$ & & & & & & & & \\
\hline \multirow[t]{2}{*}{ Medications } & Hypertensive medications & & O & $\mathrm{O}$ & O & O & $\mathrm{O}$ & $\mathrm{O}$ & O & O \\
\hline & Immunosuppressant & & O & $\mathrm{O}$ & $\mathrm{O}$ & $\mathrm{O}$ & $\mathrm{O}$ & $\mathrm{O}$ & $\mathrm{O}$ & $\mathrm{O}$ \\
\hline \multirow[t]{4}{*}{ Questionnaires } & Health questionnaires (including smoking) & & O & $\mathrm{O}$ & O & $\mathrm{O}$ & O & $\mathrm{O}$ & O & O \\
\hline & KDQOL-SF version 1.3 questionnaires & & O & $\mathrm{O}$ & $\mathrm{O}$ & $\mathrm{O}$ & $\mathrm{O}$ & $\mathrm{O}$ & $\mathrm{O}$ & $\mathrm{O}$ \\
\hline & Semi-food frequency questionnaires & & $\mathrm{O}$ & $\mathrm{O}$ & $\mathrm{O}$ & $\mathrm{O}$ & $\mathrm{O}$ & $\mathrm{O}$ & $\mathrm{O}$ & $\mathrm{O}$ \\
\hline & PedsQL 4.0 Generic Core Scales (Children) & & $\mathrm{O}$ & & & & & & & $\mathrm{O}$ \\
\hline \multirow[t]{2}{*}{ Anthropometry } & Height, weight & & $\mathrm{O}$ & $\mathrm{O}$ & $\mathrm{O}$ & $\mathrm{O}$ & $\mathrm{O}$ & $\mathrm{O}$ & & $\mathrm{O}$ \\
\hline & Blood pressure & & $\mathrm{O}$ & $\mathrm{O}$ & $\mathrm{O}$ & $\mathrm{O}$ & $\mathrm{O}$ & $\mathrm{O}$ & & $\mathrm{O}$ \\
\hline \multirow{11}{*}{$\begin{array}{l}\text { Blood laboratory } \\
\text { findings }\end{array}$} & CBC (white blood cell count, platelet, haemoglobin) & & $\mathrm{O}$ & $\mathrm{O}$ & $\mathrm{O}$ & $\mathrm{O}$ & $\mathrm{O}$ & $\mathrm{O}$ & $\mathrm{O}$ & $\mathrm{O}$ \\
\hline & $\begin{array}{l}\text { Chemistry (calcium, phosphorus, glucose, blood urea } \\
\text { nitrogen, uric acid, total protein, albumin, total } \\
\text { bilirubin, alkaline phosphatase, AST, ALT) }\end{array}$ & & O & O & O & $\mathrm{O}$ & O & O & O & O \\
\hline & IDMS-traceable Cr, eGFR & & O & O & $\mathrm{O}$ & O & $\mathrm{O}$ & $\mathrm{O}$ & O & $\mathrm{O}$ \\
\hline & $\begin{array}{l}\text { Lipid panel (total cholesterol, triglyceride, high-density } \\
\text { lipoprotein, low density lipoprotein) }\end{array}$ & & O & $\mathrm{O}$ & $\mathrm{O}$ & $\mathrm{O}$ & $\mathrm{O}$ & $\mathrm{O}$ & $\mathrm{O}$ & $\mathrm{O}$ \\
\hline & Electrolyte panel (sodium, potassium, chloride) & & O & O & $\mathrm{O}$ & O & $\mathrm{O}$ & $\mathrm{O}$ & O & $\mathrm{O}$ \\
\hline & Total $\mathrm{CO}_{2}$ & & $\mathrm{O}$ & $\mathrm{O}$ & $\mathrm{O}$ & $\mathrm{O}$ & $\mathrm{O}$ & $\mathrm{O}$ & $\mathrm{O}$ & $\mathrm{O}$ \\
\hline & C-reactive protein & & $\mathrm{O}$ & $\mathrm{O}$ & $\mathrm{O}$ & $\mathrm{O}$ & $\mathrm{O}$ & $\mathrm{O}$ & $\mathrm{O}$ & $\mathrm{O}$ \\
\hline & Serology (HBsAg, HBsAb, Anti-HCV, HIV, VDRL) & & $\mathrm{O}$ & & & & & & & \\
\hline & Anti-dsDNA, FANA, FANA titre, ANCA, PR3, MPO & & $\mathrm{O}$ & & & & & & & \\
\hline & Complement 3, 4 & & $\mathrm{O}$ & & & & & & & \\
\hline & ASO, rheumatoid factor, Cryoglobulin & & O & & & & & & & \\
\hline \multirow{5}{*}{$\begin{array}{l}\text { Urine laboratory } \\
\text { findings }\end{array}$} & Random urine protein & & $\mathrm{O}$ & $\mathrm{O}$ & $\mathrm{O}$ & $\mathrm{O}$ & $\mathrm{O}$ & $\mathrm{O}$ & $\mathrm{O}$ & $\mathrm{O}$ \\
\hline & Random urine microalbumin & & $\mathrm{O}$ & $\mathrm{O}$ & $\mathrm{O}$ & $\mathrm{O}$ & $\mathrm{O}$ & $\mathrm{O}$ & $\mathrm{O}$ & $\mathrm{O}$ \\
\hline & Random urine creatinine & & $\mathrm{O}$ & $\mathrm{O}$ & $\mathrm{O}$ & $\mathrm{O}$ & $\mathrm{O}$ & $\mathrm{O}$ & O & $\mathrm{O}$ \\
\hline & Urinalysis protein & & $\mathrm{O}$ & $\mathrm{O}$ & $\mathrm{O}$ & $\mathrm{O}$ & $\mathrm{O}$ & $\mathrm{O}$ & $\mathrm{O}$ & $\mathrm{O}$ \\
\hline & Urinalysis RBC & & O & $\mathrm{O}$ & $\mathrm{O}$ & $\mathrm{O}$ & $\mathrm{O}$ & $\mathrm{O}$ & O & $\mathrm{O}$ \\
\hline \multirow[t]{4}{*}{ Kidney biopsy } & Biopsy results and images including LM, IF and EM & & $\mathrm{O}$ & & & & & & & \\
\hline & Report of diagnosis & & $\mathrm{O}$ & & & & & & & \\
\hline & Total number of glomeruli & & $\mathrm{O}$ & & & & & & & \\
\hline & $\begin{array}{l}\text { Total number of global sclerosis/segmental } \\
\text { sclerosis/crescent }\end{array}$ & & O & & & & & & & \\
\hline \multirow[t]{4}{*}{ Biospecimens } & Serum/plasma/buffy coat/genomic DNA sample & & O & $\mathrm{O}$ & $\mathrm{O}$ & $\mathrm{O}$ & $\mathrm{O}$ & $\mathrm{O}$ & $\mathrm{O}$ & $\mathrm{O}$ \\
\hline & Urine sample & & $\mathrm{O}$ & $\mathrm{O}$ & $\mathrm{O}$ & $\mathrm{O}$ & $\mathrm{O}$ & $\mathrm{O}$ & $\mathrm{O}$ & $\mathrm{O}$ \\
\hline & Stool sample & & $\mathrm{O}$ & & & & & & & \\
\hline & $\begin{array}{l}\text { CDNA from glomeruli and tubules in micro-dissected } \\
\text { kidney biopsy tissues }\end{array}$ & & $\mathrm{O}$ & & & & & & & \\
\hline
\end{tabular}

CBC complete blood count; KDQOL-SF Kidney Disease-Quality of Life Short Form; PedsQL Pediatric Quality of Life Inventory; AST aspartate aminotransferase; ALT alanine aminotransferase; HCV hepatitis C virus; HIV human immunodeficiency virus; VDRL veneral disease research laboratory test; FANA fluorescent antinuclear antibody; MPO myeloperoxidase; $A S O$ antistreptolysin O; RBC red blood cell; LM light microscopy; IF immunofluorescent; EM electron microscopy; IDMS isotope dilution mass spectrometry; $\mathrm{Cr}$ creatinine; $e$ GFR estimated glomerular filtration rate; $Y$ year 
Table 2 Minimum detectable hazard ratio for time-to-event outcomes

\begin{tabular}{lll}
\hline Outcome & $\begin{array}{l}5 \text {-year } \\
\text { event rates }\end{array}$ & $\begin{array}{l}\text { MDHR }^{\mathbf{a}} \text { for } \boldsymbol{n}=3000 \\
(1500 / \text { group })\end{array}$ \\
\hline ESRD & 0.12 & 1.36 \\
Death & 0.06 & 1.54 \\
Complete remission of & $0.63-0.97$ & $1.14-1.17$ \\
proteinuria $(<0.3 \mathrm{~g} / \text { day })^{b}$ & & \\
\hline
\end{tabular}

Abbreviations: MDHR minimum detectable hazard ratio; ESRD end-stage renal disease

${ }^{a} \mathrm{MDHR}$ is based on the following assumptions: patient follow-up time of 5 years (ESRD and death); a loss of follow-up rate during 5 years hypothesized total of $10 \%$; $80 \%$ power, alpha $=0.05$

${ }^{\mathrm{b}}$ Group sizes for time to complete remission of proteinuria excluded one-third of the group that was in remission at enrolment

DNA and cDNA from glomeruli and tubules in microdissected kidney biopsy tissues (Table 1). Anonymous barcodes will be printed and attached to all samples collected. Additionally, registered information, including the type, quantity, and location of biospecimens, will be uploaded to the web database. All of the samples will be subsequently collected regularly according to the standardized protocol. All of the biospecimens, including plasma, serum, buffy coat, urine, genomic DNA and stool DNA, will be stored at the National Biobank of Korea launched by the KCDC.

Blood will be stored as plasma, serum, buffy coat, and genomic DNA. From one participant in the KORNERSTONE, at least one SST tube and two EDTA tubes with blood ( $8 \mathrm{cc}$ per tube, total $24 \mathrm{cc}$ ), more than $10 \mathrm{cc}$ of urine, more than $1 \mathrm{~g}$ in 2 bottles of stool, stool DNA, and at least one core of kidney biopsy tissue will be collected. Blood and urine samples will be centrifuged for $10 \mathrm{~min}$ and will be distributed in cryotubes. Serum and plasma will be stored in a liquid nitrogen freezer ($196^{\circ} \mathrm{C}$ ), and other types of biospecimens will be stored in a deep freezer $\left(-80^{\circ} \mathrm{C}\right)$ (Table 3$)$.

For quality control of biospecimens, 7-digit Standard PREanalytical Code (SPREC), which encodes pre-processing information of biospecimens, will be assigned for each blood and urine sample [12]. Serum and plasma samples will be visually checked for haemolysis. The protocol for each biospecimen is described in the supplementary section.

\section{Digital pathology repository}

Kidney biopsy materials from enrolled patients, including glass slides scanned into high-resolution whole slide images, both stained and non-stained; digital images of

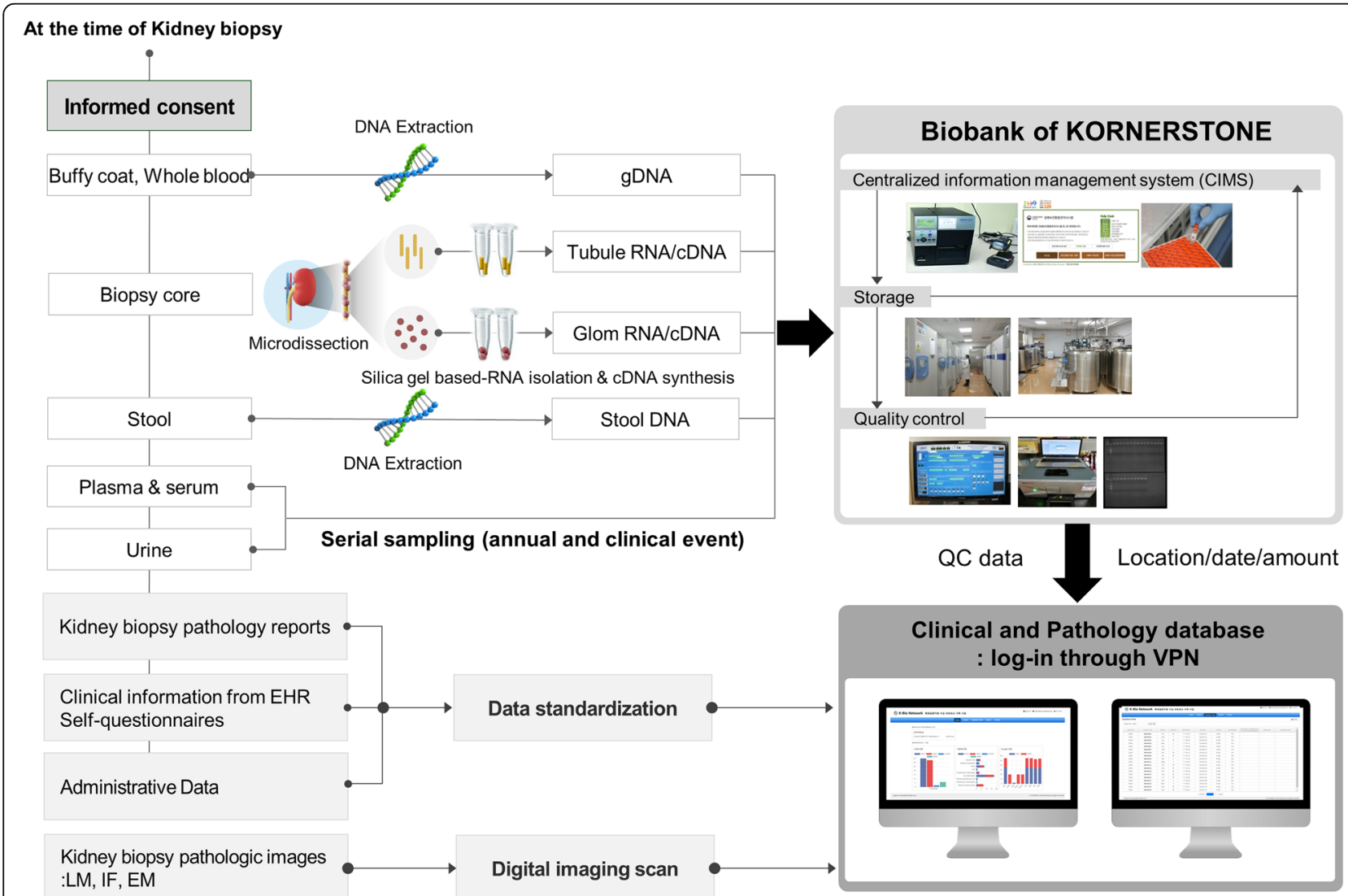

Fig. 1 Overall schemes of the KORNERSTONE. KORNERSTONE, Korea Glomerular disease Biobank Network; gDNA, genomic DNA; OPD, outpatient; EHR, electronic health record; LM, light microscopy; IF, immunofluorescence; EM, electron microscopy; QC, quality control; VPN, virtual private network 
Table 3 Overview of stored samples per participant in the KORNERSTONE

\begin{tabular}{|c|c|c|c|}
\hline Biospecimen & Stored vial & Volume and amount & Storage temperature \\
\hline \multirow[t]{2}{*}{ Serum } & $1.8 \mathrm{ml}$ cryogenic vial & Adults: $300 \mu \mathrm{l} \times 5$ vials & $\leq-196^{\circ} \mathrm{C}$ \\
\hline & & Children: $100 \mu \mathrm{l} \times 4$ vials & \\
\hline \multirow[t]{2}{*}{ Plasma } & $1.8 \mathrm{ml}$ cryogenic vial & Adults: $300 \mu \mathrm{l} \times 5$ vials & $\leq-196^{\circ} \mathrm{C}$ \\
\hline & & Children: $100 \mu \mathrm{l} \times 4$ vials & \\
\hline \multirow[t]{2}{*}{ Genomic DNA } & $1.7 \mathrm{ml}$ microcentrifuge tube & Adults: Total more than $100 \mu \mathrm{g}, 3$ vials & $\leq-80^{\circ} \mathrm{C}$ \\
\hline & & Children: Total $30 \mu \mathrm{g}, 2$ vials & \\
\hline \multirow[t]{2}{*}{ Urine } & $1.8 \mathrm{ml}$ cryogenic vial & Adults: $1 \mathrm{ml} \times 5$ vials & $\leq-80^{\circ} \mathrm{C}$ \\
\hline & & Children: $200 \mu \mathrm{l} \times 5$ vial & \\
\hline \multirow[t]{2}{*}{ Buffy coat } & $1.8 \mathrm{ml}$ cryogenic vial & Adults: $200 \mu \mathrm{l} \times 2$ vials & $\leq-80^{\circ} \mathrm{C}$ \\
\hline & & Children: $100 \mu \mathrm{l} \times 2$ vials & \\
\hline Stool DNA & $1.7 \mathrm{ml}$ microcentrifuge tube & $100 \mu \mathrm{l}, 1$ vial & $\leq-80^{\circ} \mathrm{C}$ \\
\hline Stool & $30 \mathrm{ml}$ container & $1 \mathrm{~g}, 2$ bottles & $\leq-80^{\circ} \mathrm{C}$ \\
\hline Microdissected glomerulus (cDNA) & $1.7 \mathrm{ml}$ microcentrifuge tube & Total $70 \mathrm{ng} \times 2$ vials & $\leq-80^{\circ} \mathrm{C}$ \\
\hline Microdissected tubulointerstitium (cDNA) & $1.7 \mathrm{ml}$ microcentrifuge tube & Total $100 \mathrm{ng} \times 2$ vials & $\leq-80^{\circ} \mathrm{C}$ \\
\hline
\end{tabular}

immunofluorescence and electron-micrographs; and pathologic reports from each centre will be collected and uploaded into the KORNERSTONE Digital Pathology Repository (Fig. 2). A digitizing pathology workflow was developed (HuminTec, Suwon, Korea). All of the glass slides will be scanned by Aperio AT2 (Leica Biosystems, Germany, Wetzlar). These digital image files will be stored centrally in the KreoNET server (Seoul National University Hospital, Seoul, Korea). From this system, high-quality pathology images can be acquired in a user-friendly manner and readily shared with clinicians. Before the data are sent to the central server, the study number is allocated to the pathologic images to enable the linking of pathologic data with clinical data and biospecimens. All of these images will be connected in the web-based database.

\section{Web-based database infrastructure for integration of all information}

The overall schemes of the KORNERSTONE are described in Fig. 1. All of the laboratory findings, prescribed medications, and results of pathology will be extracted from the EHR through the clinical data warehouse as Excel or csv files to reduce participants' burden. The extracted files, including laboratory and anthropometric results from each hospital, are automatically converted into a common casereport form through the macro algorithms. When the converted case-report form is uploaded to the database, different variables for each hospital can be standardized to match internal variables in the web database. The electronic web-based database management system was developed (Binarylab, Seoul, Korea). Additionally, the automatic questionnaire response system was developed for this cohort (ONCE Interactive, Seoul, Korea). Through this system, all questionnaires will be implemented using a tablet to allow patients to respond directly, and all responses are automatically stored in the web-based database.

Researchers or clinical research coordinators who want to upload or download data in the web-based database management system should log in only using a virtual private network (VPN) system to protect personal information. VPN accounts are managed by the principal investigator and clinical research associate and are only accessible by KORNERSTONE authorized staff.

\section{Governance and dissemination policy of the KORNERSTONE}

The purpose of the KORNERSTONE is to provide a foundation for the discovery of new prediction markers of glomerular diseases and the promotion of the utilization of human-derived resources within the legal and ethical regulations. Given the guidelines of future activities, the creation of governance in the KORNERSTONE is crucial. All collection of biospecimens and information and clinical and research activities will be supervised by the independent governance of KORNERSTONE (Fig. 3).

Researchers who want to use resources from the KORNERSTONE should contact initially the KCDC (biobank@ korea.kr). All of the collected data and biospecimens of the KORNERSTONE can be used only for future studies that are within the perspective of scientific objectives of the KORNERSTONE and that are approved by the Dissemination and Advisory Committee (Fig. 4). Any researchers can submit a study proposal including study objectives and the type of data and biospecimens required to the Dissemination and Advisory Committee of the KORNERSTONE. If a study proposal is approved, a new VPN account will be given to the approved researcher. All of the data will not be 


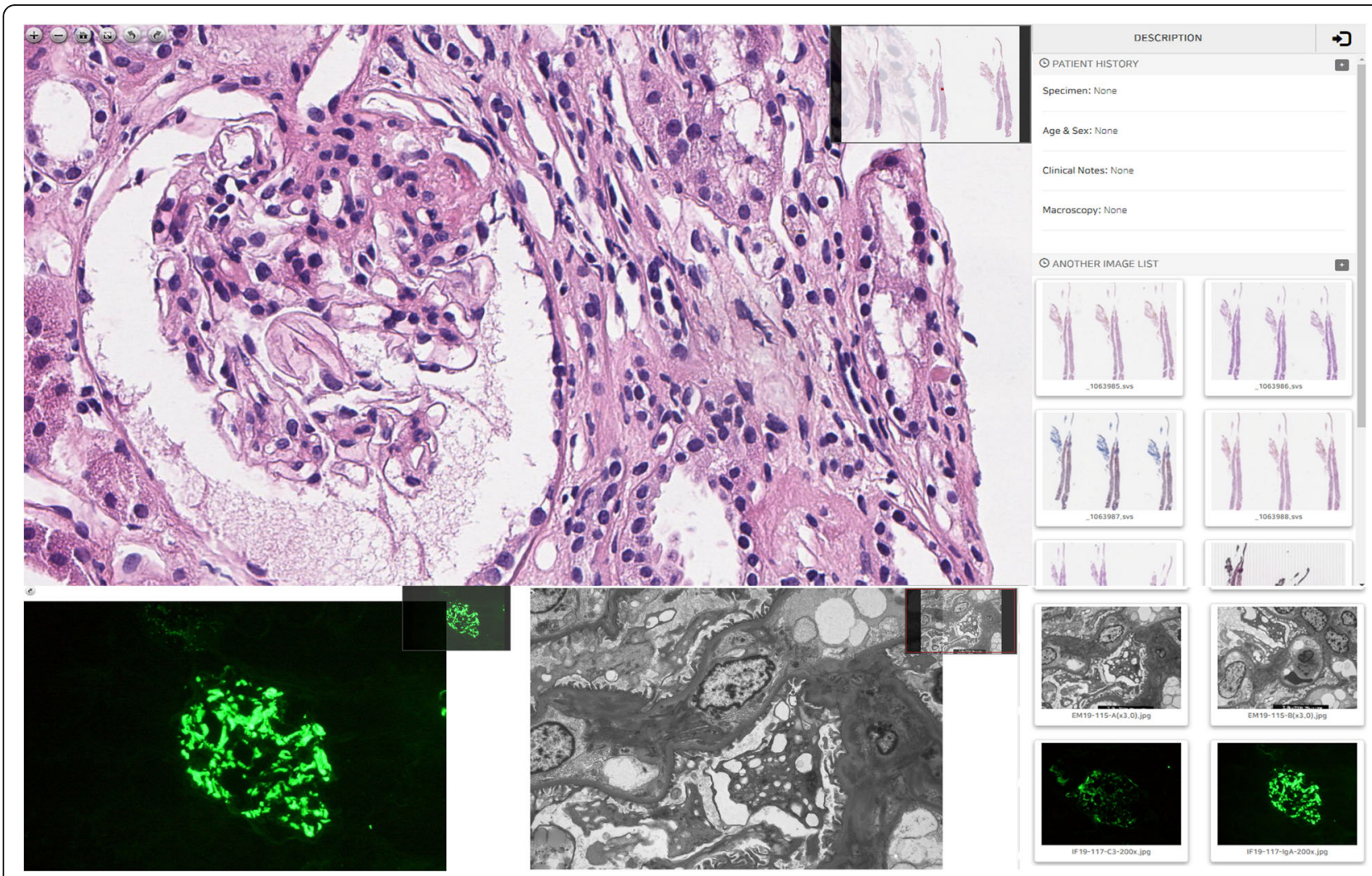

Fig. 2 Digital pathology repository. LM, light microscopy; IF, immunofluorescence; EM, electron microscopy

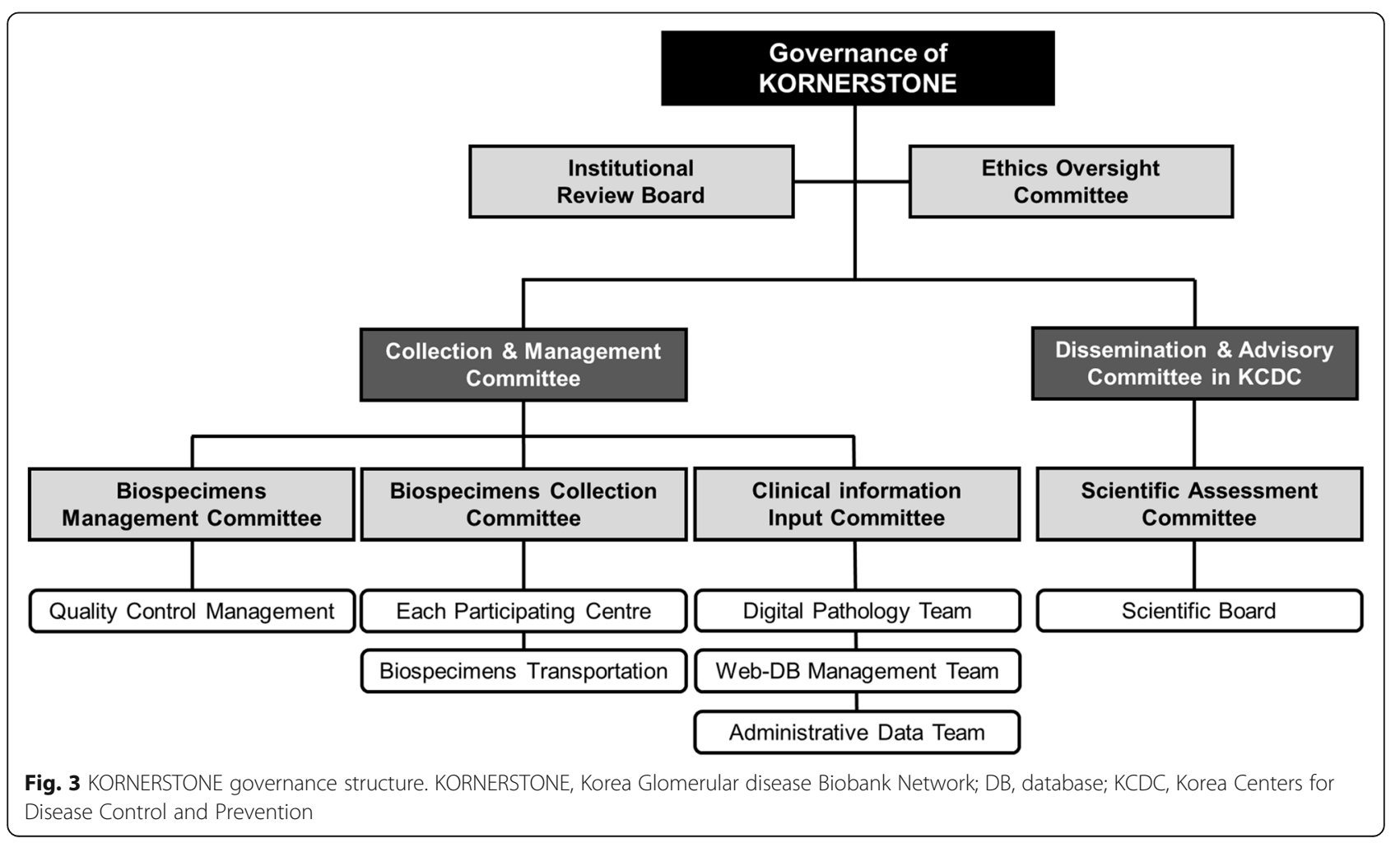




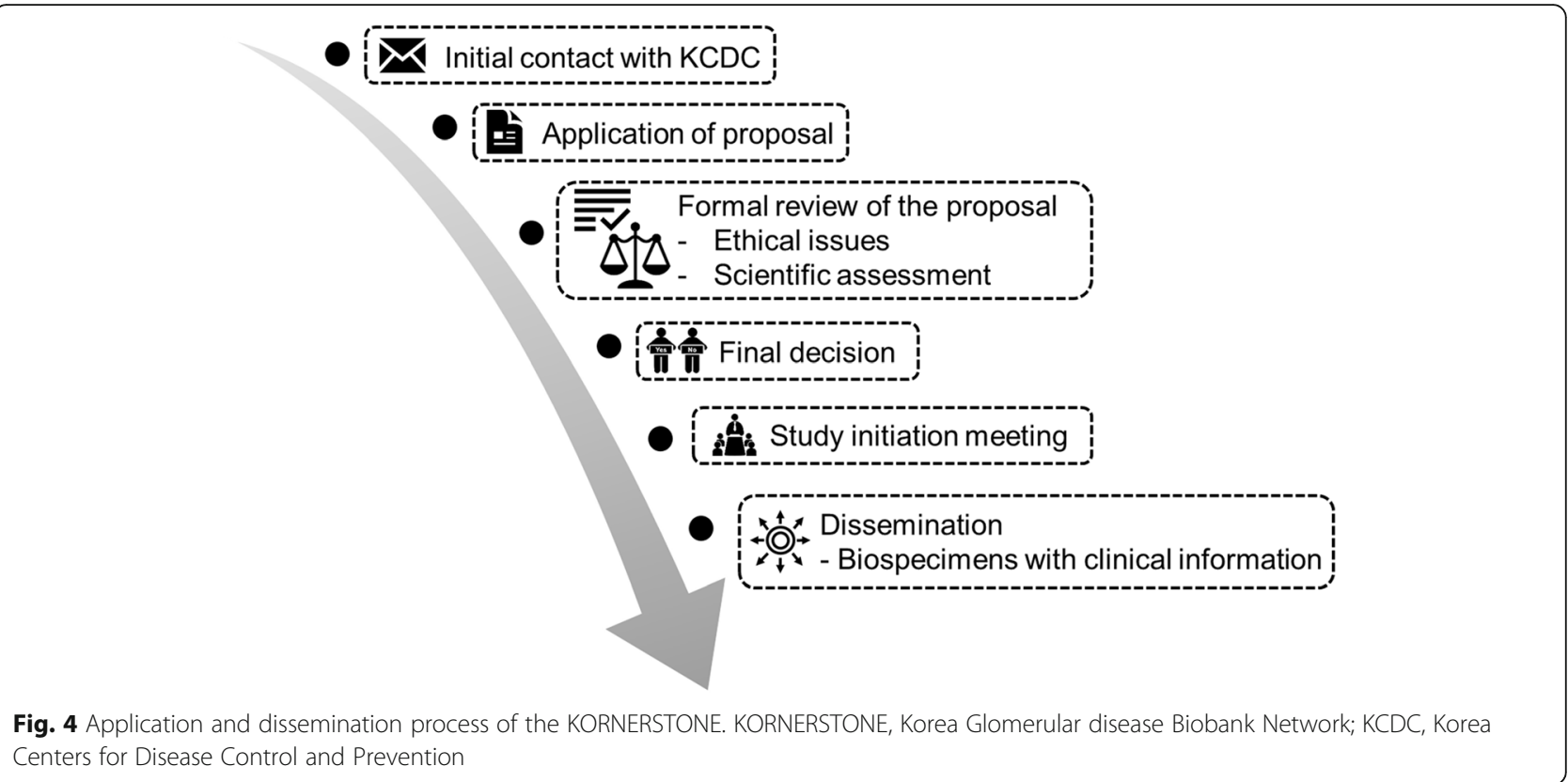

accessible, as only information and biospecimens from those patients who meet the inclusion criteria in the approved protocol will be provided to the investigators. The results of each study will be reviewed by the Scientific Assessment Committee of KORNERSTONE and will be published after peer review.

\section{Discussion}

Glomerular diseases, a set of debilitating and complex clinical disease entities affecting individuals of all ages, are associated with significant mortality and morbidity, including hospitalization and ESRD. Although there are many advances in understanding novel genetic and environmental factors affecting the pathophysiology of various glomerular diseases, there is an insufficient number of basic and translational studies that integrate clinical, pathological, and genetic information. The KORNERSTONE, a prospective cohort study with various biospecimens funded by the KCDC, was established for supporting and providing highquality clinical information and biospecimens based on deep clinical phenotypes of glomerular diseases.

The presentation and prognosis of each glomerular disease covers a wide spectrum even in the same diagnosis, and it is challenging to define each glomerular disease using only clinical descriptions [13]. This fact might be due to the classification of glomerular disease based on histopathology rather than an understanding of the molecular, genetic or environmental underpinnings of these diseases; thus, kidney biopsy is essential for a definitive diagnosis. However, a kidney biopsy is an invasive, burdensome procedure for patients, so multiple biopsy tissue collections are onerous. Misclassification of the subgrouping of glomerular diseases due to the limited reproducibility of pathologic diagnosis is another barrier for studying glomerular disease [14, 15]. While pathological review is important in diagnosis, progression or remission is identified by clinical phenotypes, including proteinuria or eGFR. Considering the chronic pathway of glomerular diseases, a deep clinical phenotype linked serially to obtained biospecimens will be a complementary substitute for the gap between pathology and clinical phenotype regarding time and precision. Thus, in-depth knowledge of each of these glomerular diseases is needed to provide effective care for the patients. Based on this background, many researchers agreed that the practice of personalized and precision medicine is necessary for this disease entity [16]. Precision medicine proposes the development of new disease definitions achieved by a multilayered multi-omics analysis of the disease course [17]. These kinds of studies provide comprehensive information along with the genotype-phenotype continuum, and it is inevitable to establish a systemic biobank that includes well-organized clinical data, evaluation of environmental factors and collection of biospecimens. From this point of view, several prospective observational cohort studies for glomerulonephritis were established: the Toronto Glomerulonephritis Registry, [18, 19] the University of North Carolina Glomerular Disease Collaborative Network, [20, 21] PodoNet, [22, 23], the British Columbia Glomerulonephritis Registry [24], Cure Glomerulonephropathy (CureGN), [25] and the NEPTUNE [5]. In addition, regarding biobanks, the Biobank for the Molecular Classification of Kidney Disease (BMCKD) is underway in Canada [26].

Pathology is a crucial test for the diagnosis and evaluation of prognosis for glomerular diseases. Expertise, abundant 
experience and reproducibility are critical to exact diagnostic accuracy. A digital pathology repository will be an essential tool for integrating clinical and pathological information together, and this system was introduced in this study. Through this digital pathology, misclassification for a subgroup of glomerular diseases can be reevaluated by many different pathologists and nephrologists. Additionally, with the advancement of high-resolution scanners, computing power, faster networks and file compression technology to scan glass slides, virtual slides with the digitalization of whole pathologic images have been achieved [27]. The introduction of digital pathology allows clinicians and pathologists to efficiently discuss various pathologic findings, not only text-based information. In addition, the reproducibility of diagnosis has been improved. Artificial intelligence that was utilized mainly in radiology and cardiology has been extended to pathology through digital glass slides. Advances in digital pathology and computer-aided diagnostic tools have made it possible for pathologists and nephrologists to identify unique imaging markers related to specific diseases, which leads to improvement of early detection and selection of effective treatment targets [28]. In line with this background, the KORNERSTONE will integrate digital pathologic images.

The KORNERSTONE will collect data from all patients undergoing kidney biopsy due to suspected glomerular disease, which is not limited to a specific diagnosis. Therefore, this cohort will be composed of more diverse diseases, including minimal change disease, focal segmental glomerulosclerosis, membranous nephropathy, membranoproliferative glomerulonephritis, crescentic glomerulonephritis, IgA nephropathy, and lupus nephritis, than the CureGN [25] and NEPTUNE cohorts [5]. Most of the glomerular disease cohorts have been constructed in Western countries. However, the epidemiology of glomerular diseases is different from that in Western populations, $[11,29]$ so the KORNERSTONE will be a good resource for providing Asian population data and revealing regional variation in glomerular diseases. Additionally, several studies reported that environmental factors and the microbiome can affect the development and prognosis of glomerular diseases, especially in IgA nephropathy [30-32]. The NEPTUNE cohort collected only quality of life and self-reported health data through questionnaires as patient-centred outcomes, and there were no surveys on influential factors other than outcomes. In the KORNERSTONE, environmental factors, including dietary data will be collected using semi-FFQ and food diaries, and stool samples will be gathered for further analysis of the microbiome. This approach will allow many researchers to evaluate in additional detail the impact of environmental factors on glomerular diseases.

One of the strong points of this cohort, administrative data from various government institutions, including HIRA, NHIS, Statistics Korea and the ESRD registry, linked by social security number will be collected. In particular, Korea achieved nationwide health insurance covering its whole population in 1989 [33], and all medical billing data for the total Korean population is included in NHIS and HIRA data. Researchers can achieve full inspection of clinical hard outcomes. Through this method, it is possible to identify all of the clinical outcomes even when the outcomes occur in other hospitals and for patients not enrolled in the clinical centre. Last, after the enrolment, each time the participant visits the hospital, we will check whether they reached the clinical outcomes. Even if there is no event, we collect clinical data and biospecimens every year. Through this followup plan, all of the clinical outcomes will be confirmed as soon as possible, and small differences will be detected that are clinically meaningful. Importantly, we can collect diverse and serial biospecimens. In this regard, it is possible to perform further analysis for risk factors of a rapid deterioration of renal function and refine the natural course of each glomerular disease.

In conclusion, we describe the objectives and clinical protocol for the KORNERSTONE. As the first large-scale glomerulonephropathy cohort study with the integration of clinical data, biospecimens and digital pathologic images in Korea, the KORNERSTONE will help to clarify the natural course, complication profiles, and novel treatment targets of the Asian population with glomerular disease. We expect that the KORNERSTONE will promote collaborative research for treatment targets for improving clinical and patient-oriented outcomes in patients with glomerular disease.

\section{Supplementary information}

Supplementary information accompanies this paper at https://doi.org/10. 1186/s12882-020-02016-z.

Additional file 1. Human biospecimen collection, quality control and standard operating procedure for each biospecimen

\section{Abbreviations}

KORNERSTONE: KOrea Renal biobank NEtwoRk System TOward NExtgeneration analysis; complementary DNA, CDNA; CKD: Chronic kidney disease; ESRD: End-stage renal disease; EHR: Electrical health record; KCDC: Korea Center for Disease Control and Prevention; MDHR: Minimum detectable hazard ratio; eGFR: Estimated glomerular filtration rate; HIRA: Health Insurance Review and Assessment Service; NHIS: National Health Insurance Service; ICD-10: International Statistical Classification of Diseases and Related Health Problems-10; IDMS: Isotope dilution mass spectrometry; CKD-EPI: Chronic Kidney Disease Epidemiology Collaboration; KDQOL-SF: Kidney Disease and Quality of Life Short Form; semi-FFQ: Semifood frequency questionnaires; SOP: Standard operating procedure; VPN: Virtual private network

\section{Acknowledgements}

The authors thank the clinical research coordinators of each participating centre for their dedication in patient recruitment and data acquisition and Medical Research Collaborating Center, Seoul National University Hospital for advice on the sample size.

KORNERSTONE: Study Group. 


\section{Clinical Centres}

Boramae Medical Center, Jung Pyo Lee, MD, Jung Nam An, MD, PhD, Jeonghwan Lee, MD, Jeonghwan Park, MD, Minjung Kim, RN, Taekyoung Kim, RN, Jinhyuk Kim.

Chung-Ang University Hospital, Jin Ho Hwang, MD, Eun A Park, Eunji Park. Kangwon National University Hospital, Ji In Park, MD, Sun Hwa Lee, MD,

Soyeong Park, Nayoung Koh.

Keimyung University Dongsan Hospital, Seungyeup Han, MD, Yaerim Kim, MD, Misun Choe, MD, Yeonghui Kim.

Seoul National University Hospital, Dong Ki Kim (Principal Investigator), MD, Kwon Wook Joo, MD, Kook-Hwan Oh, MD, Hajeong Lee, MD, Seung Seok Han, MD, Yong Chul Kim, MD, Eunjeong Kang, MD, Soojin Lee, MD, Kyung Chul Moon, MD, Hee Gyung Kang, MD, Eunyoung Kim, RN, Junghee Kim, RN, Ji Hye Park, Ji Won Jeon.

Yonsei University Severance Hospital, Jung Tak Park, MD, Beom Jin Lim, MD, Hyung Woo Kim, MD, Young Su Joo, MD, Kyungjoon Kim, RN, Bo Young Nam.

Coordinating Centre.

Seoul National University Eunyoung Kim, RN, Nankyoung Lee.

\section{Authors' contributions}

Concept and design: YK, YCK, HGK, HL, and DKK; Writing of manuscript: EK; Acquisition of data: YCK, YK, EYK, NL, YHK, SJL, SH, MC, JHH, SHL, JP, JTP, BJL, JPL, JNA, HGK, HSL, KCM, KWJ, KHO, SSH, HL, and DKK; Consultation on the questionnaires: DRR, JHK; Critical revision of the manuscript for important intellectual content: YCK, YK, and DKK; Obtained funding: DKK; All authors read and critically revised the manuscript. All authors approved the final manuscript.

\section{Funding}

This study was funded by the Korea Centers for Disease Control and Prevention (\#4845-303).

No funders had a direct role in the collection, management, analysis or interpretation of the data; preparation, nor in the decision to submit the manuscript for publication

\section{Availability of data and materials}

All of the collected data and biospecimens of the KORNERSTONE can be used only for future studies that are within the perspective of scientific objectives of the KORNERSTONE and that are approved by the Dissemination and Advisory Committee.

\section{Ethics approval and consent to participate}

The basic protocol of this study was approved by the ethics committee of each participating centre: the institutional review boards of Seoul National University (1404-117-575), Keimyung University Dongsan Hospital (DSMC 2019-04-015-001), Chung-Ang University (1942-005-369), Severance Hospital (2019-0463-001), Boramae Medical Center (L-2019-126), and Kangwon National University Hospital (KUNH-2019-05-009). Additionally, the ethics oversight committee of the KORNERSTONE reviewed the design and protocols of this study. All of the ethical issues regarding the plans of the KORNERSTONE cohort study will be supervised by this committee. Additionally, the ethics oversight committee of the KORNERSTONE reviewed the design and protocols of this study. Written informed consent will be requested from all eligible patients. Especially, parents of all children, and children themselves if age more than 6 years, provided written informed consent.

\section{Consent for publication}

Not applicable.

\section{Competing interests}

The authors declare that they have no competing interests.

\section{Author details}

'Department of Internal Medicine, Ewha Womans University Seoul Hospital, Ewha Womans University College of Medicine, Seoul, South Korea. ${ }^{2}$ Department of Internal Medicine, Keimyung University School of Medicine, Daegu, South Korea. ${ }^{3}$ Department of Internal Medicine, Seoul National University Hospital, Seoul National University College of Medicine, Seoul, South Korea. ${ }^{4}$ Seoul National University Hospital Clinical Trial Centre, Seoul, South Korea. ${ }^{5}$ Seoul National University Hospital Human Biobank, Seoul,
South Korea. ${ }^{6}$ Division of Nephrology, Department of Internal Medicine, Keimyung University Dongsan Hospital, Daegu, South Korea. ${ }^{7}$ Department of Pathology, Keimyung University School of Medicine, Daegu, South Korea. ${ }^{8}$ Department of Internal Medicine, Chung-Ang University Hospital, Seoul, South Korea. ${ }^{9}$ Division of Nephrology, Department of Medicine, Kangwon National University Hospital, Kangwon National University School of Medicine, Chuncheon, Gangwon-do, South Korea. ${ }^{10}$ Department of Internal Medicine, College of Medicine, Institute of Kidney Disease Research, Yonsei University, Seoul, South Korea. ${ }^{11}$ Department of Pathology, Yonsei University College of Medicine, Seoul, South Korea. ${ }^{12}$ Department of Internal Medicine Seoul National University Boramae Medical Center, Seoul National University College of Medicine, Seoul, South Korea. ${ }^{13}$ Department of Internal Medicine, Hallym University Sacred Heart Hospital, Anyang, South Korea. ${ }^{14}$ Department of Home Economics Education, Major of Food and Nutrition, Pai Chai University, Daejeon, South Korea. ${ }^{15}$ Department of Paediatrics, Seoul National University Children's Hospital, Seoul National University College of Medicine, Seoul, South Korea. ${ }^{16}$ Department of Pathology, Hankook Renal Pathology Lab, Seoul, South Korea. ${ }^{17}$ Department of Pathology, Seoul National University Hospital, Seoul National University College of Medicine, Seoul, South Korea.

\section{Received: 21 December 2019 Accepted: 12 August 2020}

Published online: 26 August 2020

\section{References}

1. United States Renal Data System (USRDS) 2018 Annual Data Report [https:// www.usrds.org/adr.aspx]

2. Current Renal Replacement Therapy in Korea, Insan Memorial Dialysis Registry, 2018 [http://www.ksn.or.kr/rang_board/list.html?code=sinchart].

3. Troost JP, Hawkins J, Jenkins DR, Gipson DS, Kretzler M, El Shamy O, Bellovich K, Perumal K, Bhat Z, Massengill S, et al. Consent for genetic biobanking in a diverse multisite CKD cohort. Kidney Int Rep. 2018;3(6): 1267-75.

4. Schmid H, Boucherot A, Yasuda Y, Henger A, Brunner B, Eichinger F, Nitsche A, Kiss E, Bleich M, Grone HJ, et al. Modular activation of nuclear factorkappaB transcriptional programs in human diabetic nephropathy. Diabetes. 2006:55(11):2993-3003.

5. Gadegbeku CA, Gipson DS, Holzman LB, Ojo AO, Song PX, Barisoni L, Sampson MG, Kopp JB, Lemley KV, Nelson PJ, et al. Design of the Nephrotic Syndrome Study Network (NEPTUNE) to evaluate primary glomerular nephropathy by a multidisciplinary approach. Kidney Int. 2013;83(4):749-56.

6. CKDGen meta-analysis data [http://www.nhlbi.nih.gov/research/intramural/ researchers/pi/fox-caroline/ckdgenmeta-analysis-data/ckdgen-meta-analysisdata.html].

7. European Consortium for High-Throughput Research in Rare Kidney Diseases [https://www.eurenomics.eu/].

8. Troyanov S, Wall CA, Miller JA, Scholey JW, Cattran DC. Focal and segmental glomerulosclerosis: definition and relevance of a partial remission. J Am Soc Nephrol. 2005;16(4):1061-8.

9. Troyanov S, Wall CA, Miller JA, Scholey JW, Cattran DC. Idiopathic membranous nephropathy: definition and relevance of a partial remission. Kidney Int. 2004;66(3):1199-205.

10. Geddes CC, Rauta V, Gronhagen-Riska C, Bartosik LP, Jardine AG, Ibels LS, Pei Y, Cattran DC. A tricontinental view of IgA nephropathy. Nephrol Dial Transplant. 2003;18(8):1541-8.

11. Lee H, Kim DK, Oh KH, Joo KW, Kim YS, Chae DW, Kim S, Chin HJ. Mortality and renal outcome of primary glomerulonephritis in Korea: observation in 1,943 biopsied cases. Am J Nephrol. 2013;37(1):74-83.

12. Lehmann S, Guadagni F, Moore H, Ashton G, Barnes M, Benson E, Clements J, Koppandi I, Coppola D, Demiroglu SY, et al. Standard preanalytical coding for biospecimens: review and implementation of the sample PREanalytical code (SPREC). Biopreserv Biobank. 2012;10(4):366-74.

13. Hebert LA, Parikh S, Prosek J, Nadasdy T, Rovin BH. Differential diagnosis of glomerular disease: a systematic and inclusive approach. Am J Nephrol. 2013;38(3):253-66.

14. Barisoni L, Gimpel C, Kain R, Laurinavicius A, Bueno G, Zeng C, Liu Z, Schaefer F, Kretzler M, Holzman LB, et al. Digital pathology imaging as a novel platform for standardization and globalization of quantitative nephropathology. Clin Kidney J. 2017;10(2):176-87.

15. Zee J, Hodgin JB, Mariani LH, Gaut JP, Palmer MB, Bagnasco SM, Rosenberg AZ, Hewitt SM, Holzman LB, Gillespie BW, et al. Reproducibility and 
feasibility of strategies for morphologic assessment of renal biopsies using the Nephrotic syndrome study network digital pathology scoring system. Arch Pathol Lab Med. 2018;142(5):613-25.

16. Kretzler M, Sedor JR. Introduction: precision medicine for glomerular disease: the road forward. Semin Nephrol. 2015;35(3):209-11.

17. National Research Council Committee on AFfDaNToD. The National Academies Collection: Reports funded by National Institutes of Health. In: Toward Precision Medicine: Building a Knowledge Network for Biomedical Research and a New Taxonomy of Disease. Washington (DC): National Academies Press (US) National Academy of Sciences; 2011.

18. Cattran DC, Kim ED, Reich H, Hladunewich M, Kim SJ. Membranous nephropathy: quantifying remission duration on outcome. J Am Soc Nephrol. 2017;28(3):995-1003

19. Barbour SJ, Cattran DC, Kim SJ, Levin A, Wald R, Hladunewich MA, Reich HN. Individuals of Pacific Asian origin with IgA nephropathy have an increased risk of progression to end-stage renal disease. Kidney Int. 2013;84(5):1017-24.

20. Laurin LP, Gasim AM, Poulton CJ, Hogan SL, Jennette JC, Falk RJ, Foster BJ, Nachman PH. Treatment with glucocorticoids or Calcineurin inhibitors in primary FSGS. Clin J Am Soc Nephrol. 2016;1 1(3):386-94.

21. Laurin LP, Lu M, Mottl AK, Blyth ER, Poulton CJ, Weck KE. Podocyteassociated gene mutation screening in a heterogeneous cohort of patients with sporadic focal segmental glomerulosclerosis. Nephrol Dial Transplant. 2014;29(11):2062-9.

22. Lipska BS, latropoulos P, Maranta R, Caridi G, Ozaltin F, Anarat A, Balat A, Gellermann J, Trautmann A, Erdogan O, et al. Genetic screening in adolescents with steroid-resistant nephrotic syndrome. Kidney Int. 2013; 84(1):206-13.

23. Trautmann A, Bodria M, Ozaltin F, Gheisari A, Melk A, Azocar M, Anarat A, Caliskan S, Emma F, Gellermann J, et al. Spectrum of steroid-resistant and congenital nephrotic syndrome in children: the PodoNet registry cohort. Clin J Am Soc Nephrol. 2015;10(4):592-600.

24. Barbour S, Beaulieu M, Gill J, Djurdjev O, Reich H, Levin A. An overview of the British Columbia glomerulonephritis network and registry: integrating knowledge generation and translation within a single framework. BMC Nephrol. 2013;14:236.

25. Mariani LH, Bomback AS, Canetta PA, Flessner MF, Helmuth M, Hladunewich MA, Hogan JJ, Kiryluk K, Nachman PH, Nast CC, et al. CureGN study rationale, design, and methods: establishing a large prospective observational study of glomerular disease. Am J Kidney Dis. 2019;73(2):218-29.

26. Muruve DA, Mann MC, Chapman K, Wong JF, Ravani P, Page SA Benediktsson $\mathrm{H}$. The biobank for the molecular classification of kidney disease: research translation and precision medicine in nephrology. BMC Nephrol. 2017;18(1):252.

27. Tizhoosh HR, Pantanowitz L. Artificial intelligence and digital pathology: challenges and opportunities. J Pathol Inform. 2018;9:38.

28. Niazi MKK, Parwani AV, Gurcan MN. Digital pathology and artificial intelligence. Lancet Oncol. 2019;20(5):e253-61.

29. Suryawanshi M, Karnik S, Roy S. Clinicopathological Analysis of Glomerular Disease of Adult Onset Nephrotic Syndrome in an Indian Cohort- A Retrospective Study. J Clin Diagn Res. 2017;11(5):Ec25-ec30.

30. Cheung CK, Barratt J. Gluten and IgA nephropathy: you are what you eat? Kidney Int. 2015;88(2):215-8.

31. Sato M, Kojima H, Takayama K, Koshikawa S. Glomerular deposition of food antigens in IgA nephropathy. Clin Exp Immunol. 1988;73(2):295-9.

32. Coppo R. The intestine-renal connection in IgA nephropathy. Nephrol Dial Transplant. 2015;30(3):360-6.

33. Cheol Seong S, Kim YY, Khang YH, Heon Park J, Kang HJ, Lee H, Do CH, Song JS, Hyon Bang J, Ha S, et al. Data resource profile: the National Health Information Database of the National Health Insurance Service in South Korea. Int J Epidemiol. 2017;46(3):799-800

\section{Publisher's Note}

Springer Nature remains neutral with regard to jurisdictional claims in published maps and institutional affiliations.

Ready to submit your research? Choose BMC and benefit from:

- fast, convenient online submission

- thorough peer review by experienced researchers in your field

- rapid publication on acceptance

- support for research data, including large and complex data types

- gold Open Access which fosters wider collaboration and increased citations

- maximum visibility for your research: over $100 \mathrm{M}$ website views per year

At $\mathrm{BMC}$, research is always in progress.

Learn more biomedcentral.com/submissions 